\title{
A Study on the Direction of Sustainable Urban Regeneration through Bibo Feng Shui
}

\author{
Dujin Song1), Yongseong Kim²) Seonkjae Song3)
}

\begin{abstract}
Although Korea has grown rapidly and developed cities based on advanced Western culture and material civilization, the need for urban regeneration for qualitative growth is now emerging due to the problems caused by development focused on quantitative growth. As each country has different natural and human environments, the urban development and regeneration methods should be implemented with model plans and action strategies according to the country's climate, geographical characteristics, and cultural sentiment. Like the introduction and application of Western urban development in the past, however, urban regeneration is also following Western success cases. Therefore, this study focuses on Bibo among the traditional Korean spatial thinking system of Feng Shui, to analyze the energy flow of heaven, earth, and man in the city with the concept of Qi (氣) of the Yin-Yang and Wu Xing (the Five Elements) and theoretically examine whether the energies influence each other, in order to research the direction of development that can be applied to sustainable urban regeneration in Korea. Based on this, we intend to use the findings of this study as the basic data for research on urban regeneration methods using Feng Shui in the future.
\end{abstract}

Keywords : Qi (氣), Bibo Feng Shui, Theory of Yin-Yang, and Wu Xing (the Five Elements), Sustainability, Urban Regeneration

\section{Introduction}

Although Korean cities achieved rapid economic growth after the Korean War, the development of Western urban culture and material civilization created difficulty to experience Korea's unique emotions and culture in urban spaces, which were originally intended to coexist in

Received(November 26, 2018), Review Result(1st: December 18, 2018, 2nd: January 24, 2019), Accepted(March 10, 2019)

1) (Student) 02707 Dept. Architecture Design of Master's Course, Kookmin Univ., Jungnung-dong, Seongbuk-gu, Seoul, Korea

email: songdujin@naver.com

2) (Professor, Corresponding Author) 02707 Dept. Architecture Design of Professor, Kookmin Univ., Jungnung-dong, Seongbuk-gu, Seoul, Korea

email: yongkim@korea.kr

3) (Professor) 02707 Dept. Architecture Design of Professor, Kookmin Univ., Jungnung-dong, Seongbuk-gu, Seoul, Korea

email: qna_j@qna-lab.com 
harmony with nature. In terms of Seoul, which was developed with a focus on quantitative growth, the urban area expanded to $605 \mathrm{kmit}^{2}$ which was previously $268 \mathrm{kith}^{2}$ in the past half-century. Although the city developed into a place to live for 10 million citizens from the ruins and unauthorized shanty towns in the past, there was a lack of consideration for the socially vulnerable, and historical assets were also damaged. The need for urban regeneration continues to emerge in order to reflect on the quantitative growth of the current era of growth, which is at a crossroads into the low-growth period after rapid growth. The pursuit of qualitative growth is also sought through healing and recovery, communication and consideration, and cooperation and innovation[1]. However, the urban regeneration methods are also following Western cases of success similar to those of urban development[2]. While it is important to accept international success cases, this study intends to examine an approach for sustainable urban regeneration by approaching the unique history, culture, and social assets of Korea with an organic concept. Therefore, the purpose of this study is to examine the correlation between sustainable urban regeneration and Bibo Feng Shui, among the traditional Korean spatial thinking system of Feng Shui theory and to build a foundation for future urban regeneration plans using Feng Shui theory.

In terms of the research method, we first grasped the purpose of research and planned the method. Second, we examined the concept of Qi (氣) through sustainable urban regeneration, Feng Shui and Bibo Feng Shui, and the theory of Yin-Yang and Wu Xing. Third, we derived elements of sustainable urban regeneration using Bibo Feng Shui, and searched for an approach that can be applied to Korea.

\section{Theoretical Consideration of Bibo Feng Shui for Sustainable Cities}

\subsection{Sustainable Urban Regeneration}

According to the Seoul Metropolitan Government's Urban Regeneration Practice Manual, urban regeneration refers to the continuous improvement of physical, environmental, social, and economic conditions through the comprehensive vision and prescription of areas where problems need to be solved. According to Article 2, Clause 1-1 of the Special Act on Promotion of and Support for Urban Regeneration, the legal meaning of the term "urban regeneration" refers to the economic, social, physical, and environmental revitalization of a city that is declining due to depopulation, change of industrial structure, indiscriminate expansion 
of cities, deterioration of the dwelling condition, etc. by strengthening the local capacity, introducing and creating new functions, and utilizing the local resources[3].

Robert and Sykes (2000), pioneers of urban regeneration in the UK, argue that traditional urban rehabilitation projects focused on the final outcome of improving the physical environment, while urban regeneration projects place emphasis on procedural products for the preservation and enhancement of sustainable communities. In the end, the aim is about continuously improving urban conditions through comprehensive prescriptions in areas where problems need to be solved. Moreover, sustainable regeneration should include the city's history and background, social customs and traditions, urban culture and lifestyle, and urban technology and materials. These local factors should be reflected in the planning process to create cities with uniqueness, differentiation, identity, and history. However, there are two major problems with the current sustainable urban regeneration movement in Korea. The first is the excessive trust and reliance on Western thinking and technology, and the second is overlooking the importance of the local context[4]. The Seoul Metropolitan Government's has announced the vision of the 2030 Seoul development plan and the planned goals by 5 major issues, which emphasize that the important aspect of urban regeneration is the community and the lives of the citizens. In reality, however, it is difficult to see that the opinions of the citizens are reflected merely by looking at Ihwa Mural Village and Seoullo 7017 alone.

\subsection{Feng Shui Theory and Bibo Feng Shui}

According to [Feng Shui of our time], as the wind (風) of Feng Shui is the Qi (氣) of heaven, and the water (水) is the blood (血) of the earth, just as people breathe when they have energy, all things are represented as living organisms with the same principle as human beings[5]. That is, Feng Shui is based on the 'worldview of Qi (氣),' which observes that all things in the world are made of Qi (氣), and that nature and human beings are considered as Qi as well as beings that are influenced by Qi. Qi can be largely divided into 3 major energies expressed as the Qi of heaven (天氣), earth (地氣), and man (人氣), which are related to astronomy, geography, and human affairs. Therefore, it can be viewed as a study that is connected with time, space, and human beings, or the energy of heaven, earth, and man.

In Feng Shui theory, Bibo is a technique to refine a site to suit the people and purpose when people use the site for a certain purpose[6]. It refers to creating a suitable environment by fixing the excessively overflowing, strong, insufficient, or empty factors in the spatial location according to the logic of Feng Shui[7]. 


\subsection{Bibo Feng Shui's Theory of Yin-Yang and Wu Xing}

Bibo Feng Shui can be viewed as a technique to make a suitable location by adjusting the site's interactive Qi, and Qi can be examined through the representative theory of Yin-Yang and $\mathrm{Wu}$ Xing.

First, the Yin-Yang theory divides the different energies in the world into Yin and Yang, and is a relative concept which cannot be discussed without the other. For example, as bright is viewed as the Yin, dark is considered the Yang. The relative division of Yin and Yang according to [Feng Shui of our time] is shown in [Table 1].

[Table 1] Relative Division of Yin and Yang

\begin{tabular}{|c|c|c|}
\hline Category & Yin & Yang \\
\hline Time & Long, sad, painful, dull & Short, happy, joyful, amusing \\
\hline Space & $\begin{array}{c}\text { Earth, space, down, back, right, } \\
\text { empty, closed }\end{array}$ & $\begin{array}{c}\text { Sky, time, up, front, left, filled, } \\
\text { open }\end{array}$ \\
\hline Human & Woman/mother · daughter & Man/father $\cdot$ son \\
\hline Dynamic state & $\begin{array}{c}\text { Still, stagnant, dead, grave, } \\
\text { mountain }\end{array}$ & $\begin{array}{c}\text { Moving, flowing, alive, house, } \\
\text { water }\end{array}$ \\
\hline $\begin{array}{c}\text { Cold \& warmth light \& } \\
\text { shade }\end{array}$ & Cold, dark, night, water & Warm, bright, day, fire \\
\hline Shape quality $\cdot$ quantity & $\begin{array}{c}\text { Concave, winding, concealed, } \\
\text { soft, weak, low, short, few, small }\end{array}$ & $\begin{array}{c}\text { Convex, linear, exposed, hard, } \\
\text { strong, high, long, many, big }\end{array}$ \\
\hline
\end{tabular}

Qi is a relative concept that can be divided into Yin and Yang, but this can be influenced by the Qi of shape (形氣), quality (質氣), and quantity (量氣), which can change the Qi of Yin and Yang.

Qi can be further subdivided into 5 energies, or into the 5 elements of wood (木), fire (火), earth (土), metal (金), and water (水), which can be relatively distinguished as shown in [Table 2].

In addition, the 5 elements can be understood by 生旺奴殺洩 as shown in [Fig. 1]. The expression of the mutual influence of Qi on each element can be interpreted as follows. The Seol(洩) can be interpreted as I giving lively energy, Saeng (生) as I receiving lively energy, No (奴) as I giving murderous energy, Sal (殺) as I receiving murderous energy, and the Wang (旺) as the exchange of synergy effects, whether the energy is lively or murderous. This will allow us to determine the appropriate type of prescription to make by understanding how the surrounding environment affects each element[8]. 
[Table 2] Characteristics of $\mathrm{Wu}$ Xing (the 5 elements)

\begin{tabular}{|c|c|c|c|c|c|c|c|c|c|c|}
\hline Sort & \multicolumn{2}{|c|}{ Wood } & \multicolumn{2}{|c|}{ Fire } & \multicolumn{2}{|c|}{ Earth } & \multicolumn{2}{|c|}{ Metal } & \multicolumn{2}{|c|}{ Water } \\
\hline $\begin{array}{c}\text { Yin-Yang } \\
\text { (陰陽) }\end{array}$ & Yin & Yang & Yin & Yang & Yin & Yang & Yin & Yang & Yin & Yang \\
\hline $\begin{array}{c}\text { Heavenly } \\
\text { stem (天干) }\end{array}$ & $\begin{array}{l}\text { Jia } \\
\text { (甲) }\end{array}$ & $\begin{array}{l}\text { Yi } \\
\text { (乙) }\end{array}$ & $\begin{array}{l}\text { Bing } \\
\text { (丙) }\end{array}$ & $\begin{array}{l}\text { Ding } \\
(丁)\end{array}$ & $\begin{array}{l}\text { Wu } \\
\text { (戊) }\end{array}$ & Ji (己) & $\begin{array}{l}\text { Geng } \\
\text { (庙) }\end{array}$ & Xin (申) & $\begin{array}{l}\text { Ren } \\
\text { (I) }\end{array}$ & $\begin{array}{l}\text { Gui } \\
\text { (癸) }\end{array}$ \\
\hline \multirow{2}{*}{$\begin{array}{c}\text { earthly } \\
\text { branches/ } \\
\text { (animal) }\end{array}$} & $\begin{array}{l}\text { in/ } \\
\text { (tiger } \\
\text { ) }\end{array}$ & $\begin{array}{l}\text { myo/ } \\
\text { (rabit) }\end{array}$ & $\begin{array}{l}\text { sa/ } \\
\text { (snack) }\end{array}$ & $\begin{array}{c}\mathrm{o} / \\
\text { (horse) }\end{array}$ & $\begin{array}{c}\text { jin/ } \\
\text { (dragon) }\end{array}$ & $\begin{array}{l}\text { chuk/ } \\
\text { (ox) }\end{array}$ & $\begin{array}{c}\sin / \\
\text { (monkey) }\end{array}$ & $\begin{array}{c}\mathrm{yu} / \\
\text { (chicken) }\end{array}$ & $\begin{array}{l}\text { hae/ } \\
\text { (pig) }\end{array}$ & $\begin{array}{l}\text { ja/ } \\
\text { (rat) }\end{array}$ \\
\hline & & & & & $\begin{array}{l}\text { sul/ } \\
\text { (dog) }\end{array}$ & $\begin{array}{c}\text { mi/ } \\
\text { (sheep) }\end{array}$ & & & & \\
\hline $\begin{array}{l}\text { Cardinal } \\
\text { direction }\end{array}$ & \multicolumn{2}{|c|}{ East } & \multicolumn{2}{|c|}{ South } & \multicolumn{2}{|c|}{ Center } & \multicolumn{2}{|c|}{ West } & \multicolumn{2}{|c|}{ North } \\
\hline Season & \multicolumn{2}{|c|}{ Spring } & \multicolumn{2}{|c|}{ Summer } & \multicolumn{2}{|c|}{ Four season } & \multicolumn{2}{|c|}{ Autumn } & \multicolumn{2}{|c|}{ Winter } \\
\hline Color & \multicolumn{2}{|c|}{ Blue } & \multicolumn{2}{|c|}{ Red } & \multicolumn{2}{|c|}{ Yellow } & \multicolumn{2}{|c|}{ White } & \multicolumn{2}{|c|}{ Black } \\
\hline Taste & \multicolumn{2}{|c|}{ Sour } & \multicolumn{2}{|c|}{ Bitter } & \multicolumn{2}{|c|}{ Sweet } & \multicolumn{2}{|c|}{ Pungent } & \multicolumn{2}{|c|}{ Salty } \\
\hline Virtues & \multicolumn{2}{|c|}{ Benevolence } & \multicolumn{2}{|c|}{ Propriety } & \multicolumn{2}{|c|}{ Sincerity } & \multicolumn{2}{|c|}{ Righteousness } & \multicolumn{2}{|c|}{ Knowledge } \\
\hline $\begin{array}{l}\text { Generating } \\
\text { interaction }\end{array}$ & \multicolumn{2}{|c|}{$\begin{array}{l}\text { Wood } \\
\text { generates } \\
\text { fire }\end{array}$} & \multicolumn{2}{|c|}{$\begin{array}{l}\text { Fire generates } \\
\text { earth }\end{array}$} & \multicolumn{2}{|c|}{$\begin{array}{l}\text { Earth generates } \\
\text { metal }\end{array}$} & \multicolumn{2}{|c|}{$\begin{array}{l}\text { Metal generates } \\
\text { water }\end{array}$} & \multicolumn{2}{|c|}{$\begin{array}{c}\text { Water } \\
\text { generates } \\
\text { wood }\end{array}$} \\
\hline $\begin{array}{l}\text { Overcoming } \\
\text { interaction }\end{array}$ & \multicolumn{2}{|c|}{$\begin{array}{c}\text { Wood } \\
\text { overcomes } \\
\text { earth }\end{array}$} & \multicolumn{2}{|c|}{$\begin{array}{l}\text { Fire overcomes } \\
\text { metal }\end{array}$} & $\begin{array}{r}\text { Earth ov } \\
\text { wa }\end{array}$ & $\begin{array}{l}\text { ercomes } \\
\text { er }\end{array}$ & $\begin{array}{r}\text { Metal o } \\
\mathrm{w}\end{array}$ & $\begin{array}{l}\text { ercomes } \\
\text { od }\end{array}$ & $\begin{array}{r}\text { W } \\
\text { over } \\
\mathrm{f}\end{array}$ & $\begin{array}{l}\text { ter } \\
\text { omes } \\
\text { e }\end{array}$ \\
\hline
\end{tabular}

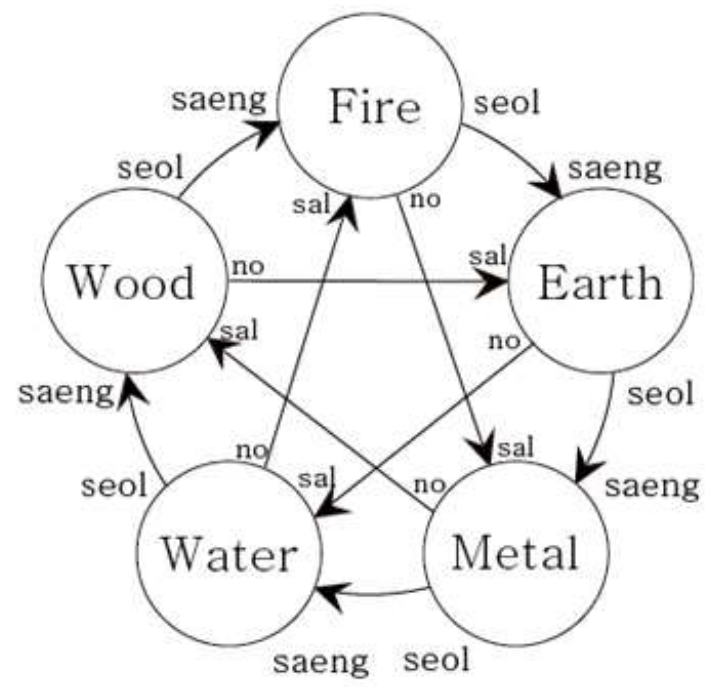

[Fig. 1] The Influence of the 5 Elements on Each Other (生旺奴殺洩) 


\subsection{Bibo Feng Shui and Sustainable Urban Regeneration}

Sustainability can be better described as an organic and cyclical thinking system rather than a linear thinking system because the past, present, and future are mutually influential[4]. [Fig. 2] cites the comparison of the Western and Feng Shui thinking systems in the 'Study of the Applicability of Korean Feng Shui Theory for Sustainable Urban Development.' Unlike past urban development and current urban regeneration methods that were implemented as a linear thinking system, the approach of Feng Shui theory, as a cyclic thinking system, enables us to study sustainable city circulation systems considering time, space, and human interaction.
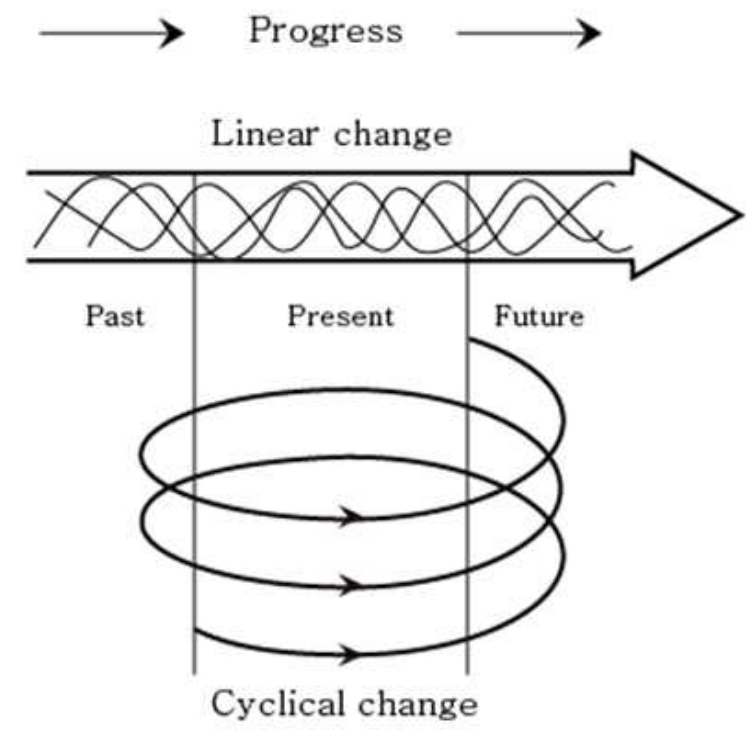

[Fig. 2] Comparison of Western Thinking Systems and Feng Shui Thinking Systems

Implementing sustainable urban regeneration is in line with building a propitious site, which is referred to as good land in Feng Shui. A good land in Feng Shui refers to a space where the people and the earth interact and harmonize with each other, as well as a place where people live together in a community, which can be viewed as building a propitious site by understanding the Qi of heaven, earth, and man from the perspective of the theory of Yin-Yang and Wu Xing. 


\section{Directions for Sustainable Urban Regeneration through Bibo Feng Shui}

\subsection{Directions for Sustainable Urban Regeneration}

The Seoul Metropolitan Government's '2025 Urban Regeneration Strategy Plan' is shown in [Fig. 3][3]. Although the categories and plans that were created to achieve sustainable urban regeneration should be considered, focusing on one side with a countermeasure of linear thinking can lead to a lack of consideration to the other side. A mutually integrated examination rather than the division of the categories of the urban regeneration plan can be viewed as a direction to create a sustainable urban circulation system.

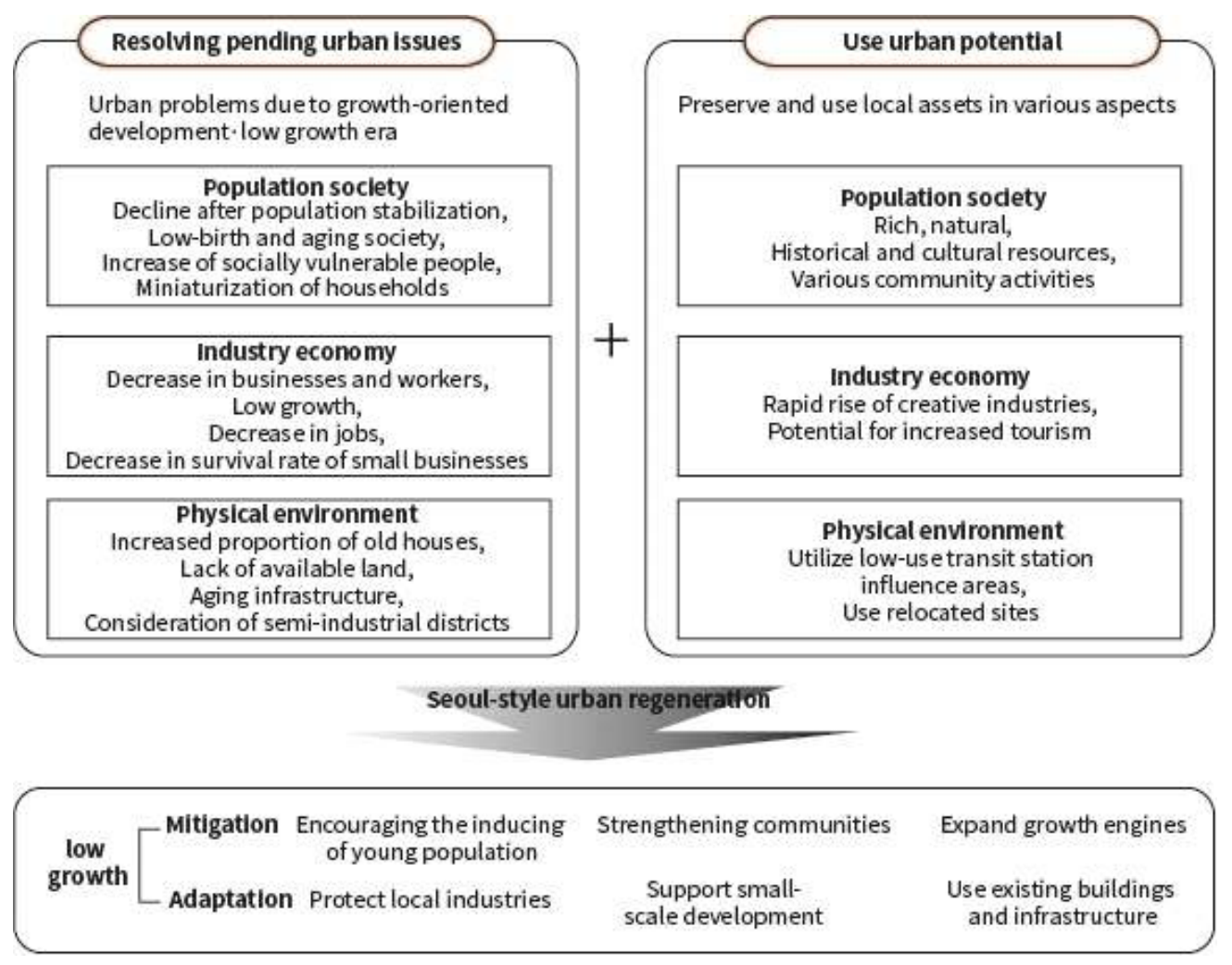

[Fig. 3] Seoul Metropolitan Government's Urban Regeneration Plan

\subsection{Sustainable Urban Regeneration from the Viewpoint of Bibo Feng Shui}

In terms of the development process of these above planning elements, we can see that they 
were all developed by the movement of people between heaven and earth. Furthermore, by analyzing the time, space, and the flow of Qi interacting with humans as a circulating thinking system and applying the Bibo concept to urban regeneration, we can create a sustainable urban circulation system that better suits the Korean culture and sentiment. [Table 3] shows the creation of sustainable urban regeneration from the viewpoint of Bibo Feng Shui.

[Table 3] Sustainable Urban Regeneration from the Viewpoint of Bibo Feng Shui

\begin{tabular}{|c|c|c|}
\hline Feng Shui & Bibo analysis theory & Sustainable urban regeneration \\
\hline Qi of heaven (天氣) & $\begin{array}{c}\text { Sexagenary cycle } \\
\text { (60-year cycle) }\end{array}$ & $\begin{array}{c}\text { Flows of the era and economy, } \\
\text { Cycle of the season }\end{array}$ \\
\hline Qi of earth (地氣) & $\begin{array}{c}\text { Qi of shape, quality, } \\
\text { and quantity }\end{array}$ & $\begin{array}{c}\text { Physical environment (location characteristics, } \\
\text { geographical location, use of buildings, surrounding } \\
\text { environment) }\end{array}$ \\
\hline Qi of man (人氣) & Yin-Yang Wu Xing & $\begin{array}{c}\text { Population society (form of movement, needs), } \\
\text { All life together with nature }\end{array}$ \\
\hline
\end{tabular}

If the fundamental concept of the Qi of heaven, earth, and man is applied to sustainable urban regeneration, the Qi of heaven (天氣) refers to reading the right time. This means that one must to have a historical understanding of the events that happened in the past to predict how the current state will change in the future. The energy of each year can be examined in advance through the sexagenary cycle (60-year cycle) based on the theory of Yin-Yang and Wu Xing, which is made from astronomical observations. Furthermore, the effects of temperature, humidity, and wind can be prepared for and supplemented by considering the energies with the circulation of seasons. The Qi of earth (地氣) refers to the need to read the characteristics, geographical location, purpose, and the interaction with the surrounding environment of the location, and above all, the need to understand the Qi of shape (形氣) to understand the form, how the flow of energy is moving, and which parts are blocked. In addition, it is possible to identify whether the use is appropriate according to the earth environment. Lastly, the Qi of man (人氣) refers to the need to read the movements of all people in heaven and earth as well as of all life forms. The energy of areas that are over-populated or areas that lay in ruin should also identify the flow of earth energy and heavenly energy to disperse the energy or to create an energizing and harmonious urban ecosystem.

All of the energies from heaven, earth, and man can be comprehensively analyzed through the theory of Yin-Yang and $\mathrm{Wu}$ Xing to understand which energy is strong and how they affect each other, and whether a location can be a good or a problematic site depending on the mutual relationship rather than the strength of one particular energy. We will be able to 
achieve sustainable urban regeneration by understanding which parts are weak and strong, identifying the changing flow of Qi that affects each other, and planning and supplementing urban regeneration.

\section{Conclusion}

Unfortunately, the rapid urbanization process centered around apartment-oriented settlements in Korea for the past 50 years has dismantled village communities and led to the disappearance of Feng Shui. At this point, there is a need to consider sustainable urban regeneration due to the reckless urban development and natural destruction that occurred after the Industrial Revolution. This study examined this issue from the viewpoint of Feng Shui which is suitable for preserving the natural characteristics and culture of Korea. Of course, it will be difficult to find ways to study urban regeneration from the perspective of Feng Shui, as current cities in Korea have been developed with Western functional development methods. In addition, much research is still needed to find ways to apply Bibo Feng Shui, which remains a traditional theory, to modern cities. However, this study firstly suggests that the cyclical thinking system of Feng Shui rather than the existing linear thinking system can create a more sustainable urban circulation system considering time, space, and human interaction. Second, it is possible to compare and analyze the concept of the Qi of heaven, earth, and man by expressing it with the theory of Yin-Yang and $\mathrm{Wu}$ Xing. Third, this study suggested a direction for sustainable urban regeneration through Feng Shui theory, a traditional Korean spatial thinking system, by understanding the current flow of energy to create a suitable environment by adjusting the excessively overflowing, strong, insufficient, or empty factors in the spatial location according to the logic of Bibo Feng Shui.

\section{References}

[1] B. S. Byeon, K. Y. Jung, Applicability of Feng Shui theory for low carbon green city planning, 2011 Korea Environmental Policy Society Fall Conference, (2011), November 2; Seoul, Korea.

[2] H. S. Oak, T. D. Chung, A Contemporary Reinterpretation toward Pungsu Geography, Journal of the Korean Geographical Society, (2013), Vol.48, No.6, pp.967-977, UCI: G704-000550.2013.48.6.001

[3] Seoul Urban Regeneration Portal, https://uri.seoul.go.kr/surc/main.do, Sept 25 (2018)

[4] C. K. Kim, K. Y. Jung, A Study on the Applicability of Korean Feng Shui Theory for Sustainable Urban 
Development, Journal of the Korean Urban Management Association, (2015), Vol.28, No.4 pp.1-30, UCI: G704-001469.2015.28.4.009

[5] I. C. Jo, Secret of Cure Feng Shui, Dasan Books, (2010)

[6] S. D. Park, The Way to Create the Korean Low Carbon Green City through the Contemporary Interpretation of the Pungsu, Journal of The Korean Association of Regional Geographers, (2014), Vol.20, No.1, pp.70-91, UCI: G704-000607.2014.20.1.003

[7] C. S. Kim, Creative Ways for the Sustainable Urban based the Theory of Feng Shui -Focuesed on the Ecological Sustainability-, Korean Local Government Congress 2012 Spring Conference, (2012), May 24; Seoul, Korea.

[8] I. C. Jo, Feng Shui of our time, Publishing Company Minsokwon, (2008) 